Marquette University

e-Publications@Marquette

$1-1-2007$

\title{
Structural Characterization of Quaterphenyl
} Cation Radical: X-ray Crystallographic Evidence of Quinoidal Charge Delocalization in Poly-pphenylene Cation Radicals

Moloy Banerjee

Marquette University

Sergey V. Lindeman

Marquette University, sergey.lindeman@marquette.edu

Rajendra Rathore

Marquette University

Accepted version. Journal of the American Chemical Society, Vol. 129, No. 26 (2007): 8070-8071.

DOI. (C) 2007 American Chemical Society. Used with permission. 
Marquette University

e-Publications@Marquette

\title{
Chemistry Faculty Research and Publications/College of Arts and Sciences
}

This paper is NOT THE PUBLISHED VERSION; but the author's final, peer-reviewed manuscript. The published version may be accessed by following the link in the citation below.

Journal of the American Chemical Society, Vol. 129, No. 26 (2007): 8070-8071. DOI. This article is (C) American Chemical Society and permission has been granted for this version to appear in ePublications@Marquette. American Chemical Society does not grant permission for this article to be further copied/distributed or hosted elsewhere without the express permission from American Chemical Society.

\section{Structural Characterization of Quaterphenyl Cation Radical: X-ray Crystallographic Evidence of Quinoidal Charge Delocalization in Poly-p-phenylene Cation Radicals}

\author{
Moloy Banerjee \\ Department of Chemistry, Marquette University, Milwaukee, WI \\ Sergey V. Lindeman \\ Department of Chemistry, Marquette University, Milwaukee, WI \\ Rajendra Rathore \\ Department of Chemistry, Marquette University, Milwaukee, WI
}




\section{Abstract}
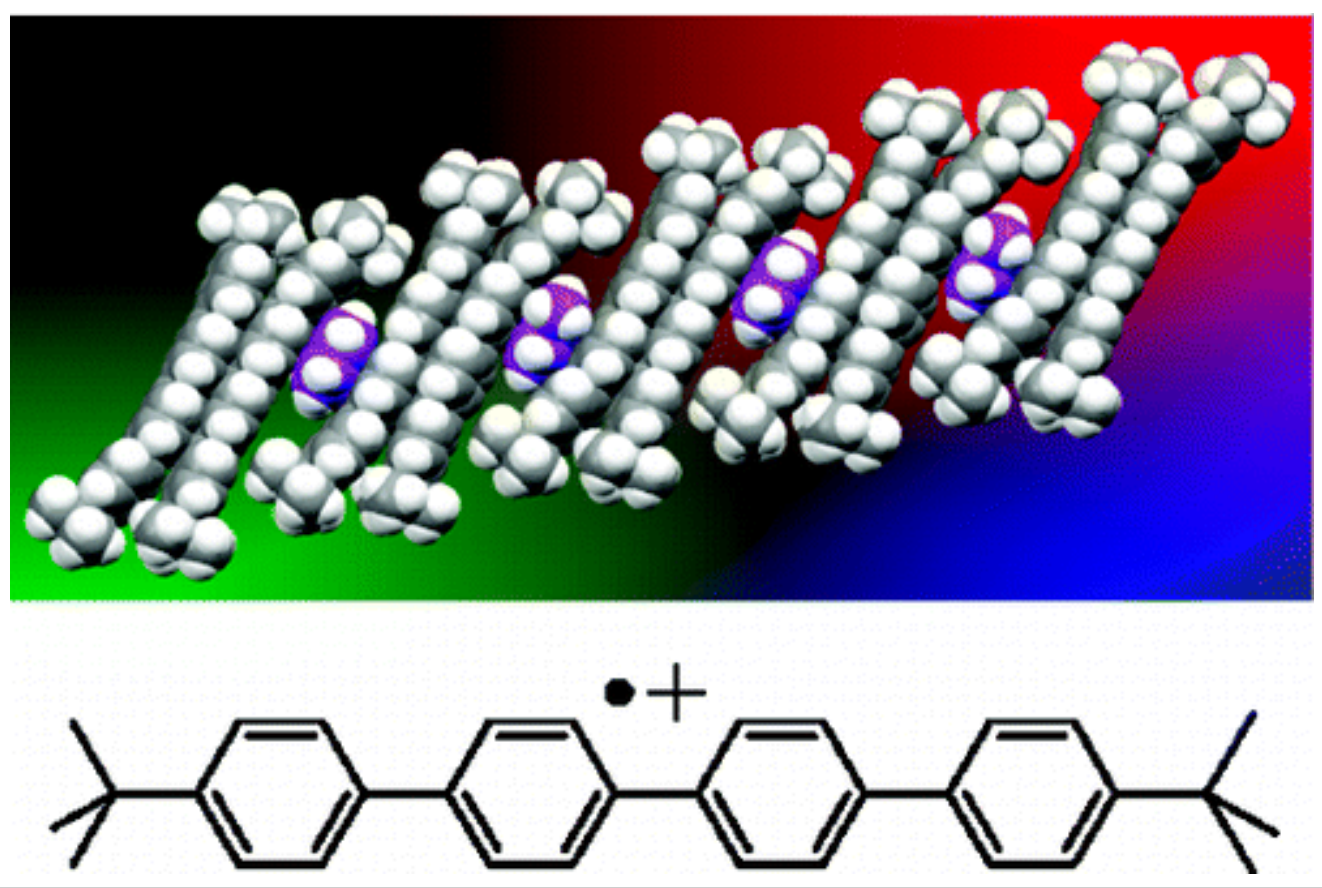

Quaterphenyl derivative (QP) containing tert-butyl solubilizing groups at the terminal positions yields a stable cation radical salt that was isolated, and its structure was established by X-ray crystallography. The crystal structure of neutral QP and its cation radical $\left(\mathrm{QP}^{+\bullet} \mathrm{SbCl}_{6}{ }^{-}\right)$provides unequivocal evidence for the quinoidal stabilization of the cationic charge or polaron by smoothing out the torsional motion of the interconnected $p$ phenylene rings. Such an observation of stabilization of the cationic charge in a poly-p-phenylene (PPP) derivative forms the basis for the noted high conductivities in PPP oligomers in their doped state.

The study of $\pi$-conjugated oligomers and polymers has attracted considerable attention since these materials hold promise for applications in the emerging area of molecular electronics and nanotechnology. ${ }^{1}$ Of these, poly- $p$-phenylenes (PPP) are especially important due to their optoelectronic properties, ${ }^{2}$ high conductivity when doped with either $n$ - or $p$-type dopants, ${ }^{3}$ potential usage as active constituents of blue light emitting diodes, ${ }^{4}$ and high thermal and oxidative stability. ${ }^{5}$ Unfortunately, their lack of processability, especially when they are unsubstituted, has hampered their study as well as exploitation of their extensive potential for practical applications. ${ }^{6}$

Several studies have been conducted where PPP oligomers have been utilized as spacers or bridges in molecular assemblies consisting of electron donor-bridge-electron acceptor (D-B-A) to explore their potential as functional molecular wires for long-range electron transport. ${ }^{7}$ The mechanism of charge transport (CT) in these assemblies is proposed to occur by a combination of highly distance-dependent coherent (i.e., superexchange) and weakly distance-dependent noncoherent (i.e., hopping) mechanisms. ${ }^{7}$ In order to gain a better understanding of various CT mechanisms operating in these PPP-based molecular wires, a quantitative understanding as to how the charge is stabilized by multiple aryl moieties that constitute the spacer is highly desirable. Therefore, attempts to isolate an oxidized 
polyphenyl cation radical to gain X-ray crystallographic evidence as to how the creation of a hole leads to structural changes in various PPPs are pertinent. We have recently undertaken studies to this effect, and herein we report the isolation of both the neutral as well as the cation radical salt of a quaterphenyl derivative (QP) having tert-butyl solubilizing groups at the terminal positions, enabling us to unequivocally establish from the crystallographic parameters that a single charge is delocalized by a quinoidal distortion of the phenylene rings. It is also noted that the tert-butyl substitutions at terminal positions in larger PPP oligomers merely aid in improving their solubility without affecting the electronic properties to any significant extent as the HOMO resides largely on the central phenylene rings. ${ }^{8}$ The details of these preliminary finding are discussed herein.

The 4,4" "'-di-tert-butylquaterphenyl was prepared from 4,4" '-diiodobiphenyl and 4-tertbutylphenylboronic acid via a $\mathrm{Pd}(0)$-mediated Suzuki reaction in $67 \%$ yield and was purified by crystallizations from a $\mathrm{CHCl}_{3}-\mathrm{MeOH}$ mixture (see Supporting Information for the experimental details and spectral data).

Next, the quaterphenyl derivative was subjected to electrochemical oxidation at a platinum electrode as a $2 \times 10^{-3} \mathrm{M}$ solution in dichloromethane containing $0.2 \mathrm{Mn}-\mathrm{Bu}_{4} \mathrm{NPF}_{6}$ as the supporting electrolyte. The cyclic voltammograms (Figure $1 \mathrm{~A}$ ) consistently met the reversibility criteria at various scan rates of $25-400 \mathrm{mV} / \mathrm{s}$, as they all showed cathodic/anodic peak current ratios of $i_{\mathrm{a}} / i_{\mathrm{c}}=1.0$ (theoretical) as well as the differences between anodic and cathodic peak potentials of $E_{\mathrm{pa}}-E_{\mathrm{pc}} \sim 70 \mathrm{mV}$ at $22^{\circ} \mathrm{C}$. The reversible oxidation potential was calibrated with ferrocene as internal standard ( $E_{\mathrm{ox}}=0.45 \mathrm{~V}$ vs SCE) and was found to be $1.47 \mathrm{~V}$ versus SCE corresponding to the formation of a monocation. 

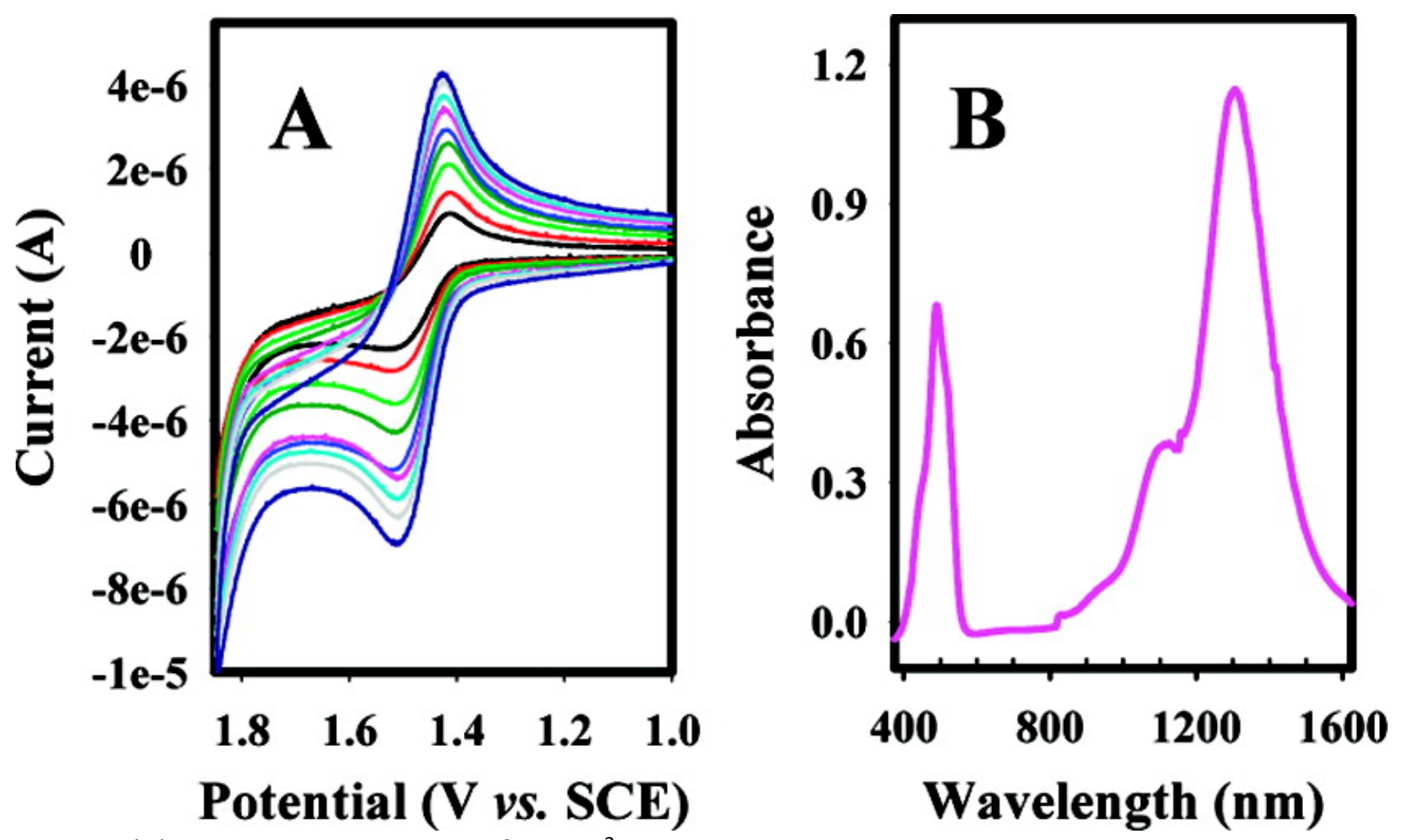

Figure 1 (A) Cyclic voltammograms of $2 \times 10^{-3} \mathrm{M}$ QP in $\mathrm{CH}_{2} \mathrm{Cl}_{2}$ containing $0.1 \mathrm{M} n-\mathrm{Bu}_{4} \mathrm{NPF}_{6}$ at scan rates between 25 and $400 \mathrm{mV} \mathrm{s}^{-1}$, and (B) UV-vis absorption spectrum of cation radical $\mathrm{QP}^{+\bullet}$ obtained by $\mathrm{NO}^{+} \mathrm{SbCl}_{6}^{-}$oxidation in dichloromethane at $22^{\circ} \mathrm{C}$.

The high electrochemical reversibility of oxidation of QP prompted us to isolate its cation radical in solution by chemical oxidation using nitrosonium hexachloroantimonate as a 1-e- oxidant according to the stoichiometry in eq 1.

$$
\mathrm{QP}+\mathrm{NO}^{+} \mathrm{SbCl}_{6}{ }^{-} \frac{\mathrm{DCM}}{-10^{\circ} \mathrm{C}} \mathrm{QP}^{+*} \mathrm{SbCl}_{6}^{-}+\mathrm{NO}^{+}
$$

Thus, a solution of QP in anhydrous dichloromethane was added to crystalline $\mathrm{NO}^{+} \mathrm{SbCl}_{6}^{-}$under an argon atmosphere at $-10{ }^{\circ} \mathrm{C}$. The gaseous nitric oxide produced was entrained by bubbling argon through the solution to yield a deep red solution, which upon spectrophotometric analysis indicated the formation of $\mathrm{QP}^{+\bullet} \mathrm{SbCl}_{6}{ }^{-}$as judged by the appearance of characteristic twin absorption bands at $\lambda_{\max }=490$ and $1302 \mathrm{~nm}$ (Figure 1B). ${ }^{9}$ Twin absorption bands in $\mathrm{QP}^{+\bullet}$ are reminiscent of the absorption bands observed in the spectrum of the biphenyl cation radical generated by laser flash photolysis or pulse radiolysis. ${ }^{10}$ The molar extinction coefficient of pink-red QP+• was estimated to be $54800 \pm 3000$ $\mathrm{M}^{-1} \mathrm{~cm}^{-1}$ (see Supporting Information).

The stability of the $\mathrm{QP}^{+\bullet} \mathrm{SbCl}_{6}^{-}$prompted us to attempt the isolation of its crystalline salt as follows. For example, an excellent crop of dark red crystals, suitable for X-ray crystallographic studies, were 
obtained by a slow diffusion of toluene in a dichloromethane solution of $\mathrm{QP}^{+\bullet} \mathrm{SbCl}_{6}^{-}$during a period of 2 days at $-30^{\circ} \mathrm{C}$.

The crystal structure of the $\mathrm{QP}^{+\bullet} \mathrm{SbCl}_{6}^{-}$revealed that two symmetrically independent molecules of $\mathrm{QP}^{+\bullet}$ having essentially the same structure are stacked as dimeric pairs which are separated by intercalated toluene molecules, as shown in Figure 2. The close interplanar distance between the two $\mathrm{QP}^{+\bullet}$ in the dimeric pair of $\sim 3.1 \AA$, which is less than the equilibrium van der Waals separation of $3.4 \AA$, is indicative of electronic coupling between them. ${ }^{11}$ Such a close packing of the $\mathrm{QP}^{+\bullet}$ in dimeric pairs leads to a slight longitudinal displacement with respect to each other to compensate for the steric crowding caused by the terminal tert-butyl groups.
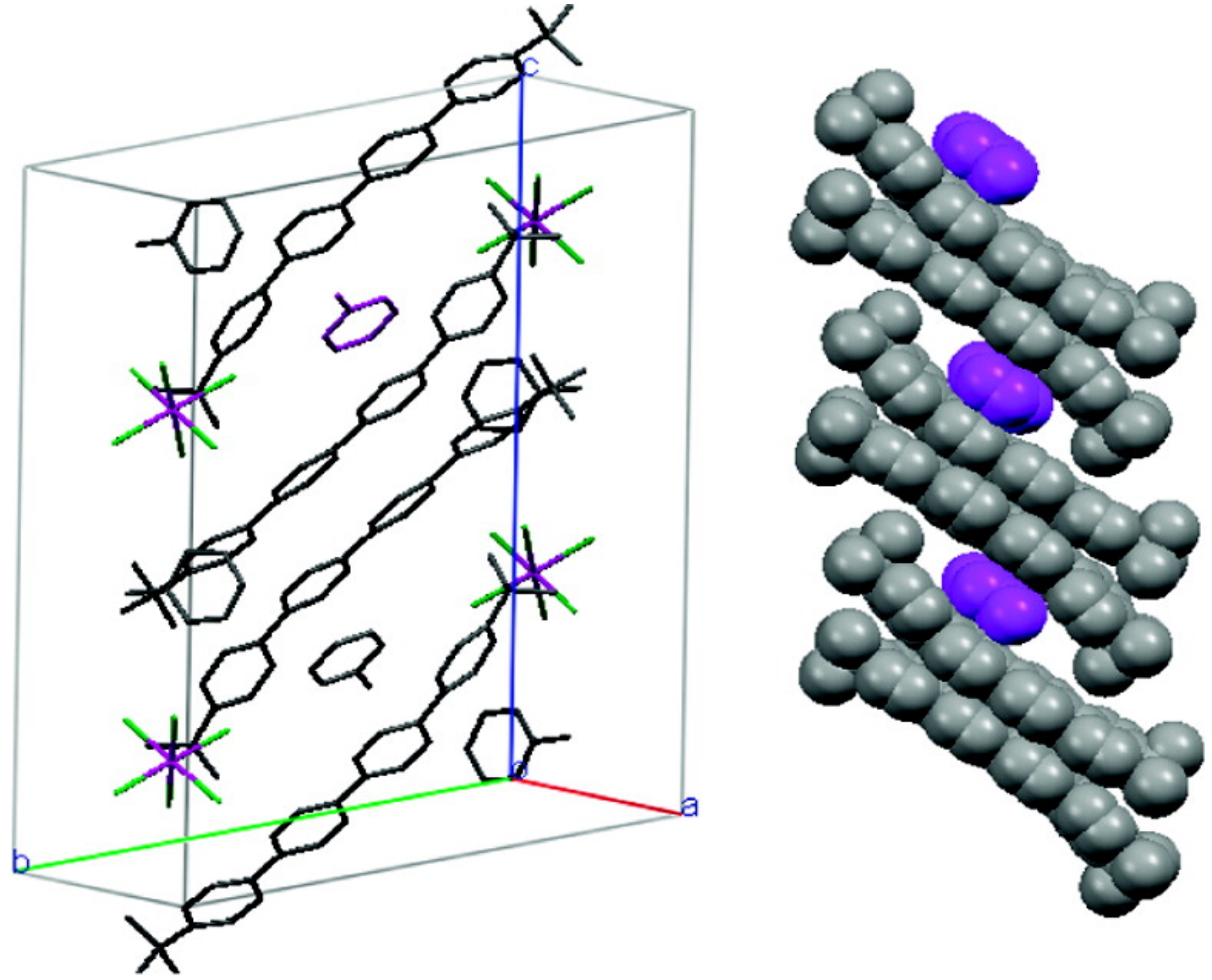

Figure 2 The crystal structure of $\mathrm{QP}^{+\bullet} \mathrm{SbCl}_{6}{ }^{-}$cation radical, with the packing diagram showing that the toluene molecules are embedded between the stacked dimeric pairs. 
A closer look at the structural parameters of the cation radical $\mathrm{QP}^{+\bullet}$, along with a comparison with its neutral form, points to four important observations: (i) The central bond distance of $1.440 \AA$ between the two inner benzene rings $B$ and $C$ in $Q^{+\bullet}$ is considerably shorter than the two peripheral $C-C$ bonds between the outer rings and the penultimate ones (i.e., 1.454 $\AA$ between rings $A$ and $B$ and $1.463 \AA$ between rings $\mathrm{C}$ and $\mathrm{D}$ ). This represents a contraction of the central $\mathrm{C}-\mathrm{C}$ bond (between ring $\mathrm{B}$ and $\mathrm{C}$ ) by $5 \mathrm{pm}$ in the oxidized form in comparison to $1.1 \mathrm{pm}$ in neutral QP. ${ }^{12}$ (ii) The longitudinal bonds inside the rings are contracted, whereas the transverse bonds are lengthened in comparison to neutral QP, indicative of a quinoidal bond alteration. ${ }^{13}$ In numerical terms, the longitudinal bond contraction results in bond lengths of $1.377 \AA$ (ring A), $1.362 \AA$ (ring B), $1.368 \AA$ (ring C), and $1.381 \AA$ (ring D) from an average of $1.38 \AA$ in the neutral QP and a consequent lengthening of the transverse bonds to

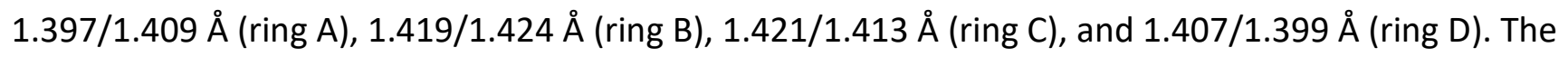
magnitude of the bond contractions and expansions reaches a maximum in the inner rings with the peripheral rings being less affected. (iii) The torsional angles between the rings $A / B / C$ are $\sim 0.1-15^{\circ}$, resulting in a nearly coplanar conformation. However, for the peripheral ring $D$, this angle slightly increases primarily due to the steric hindrance of the tert-butyl group of the adjacent stacked molecule. Thus, the formation of the cation radical smooths out the torsional motion of the interconnected aryl rings from their typical values of $\sim 30^{\circ}$ between the outer rings and $\sim 10^{\circ}$ between the central rings as in the neutral form, in order to allow effective stabilization of the cationic charge by quinoidal distortions. ${ }^{13}$ (iv) Considering the magnitude of quinoidal distortion to be a linear function of the amount of charge allocated within the corresponding ring, we can estimate that the rings A-D bear the following positive charges: 0.15 e (A), 0.46 e (B), 0.33 e (C), and 0.06 e (D). As such, the asymmetric charge distribution further attests to the strong electronic coupling within the "shifted" dimeric associates. ${ }^{11}$

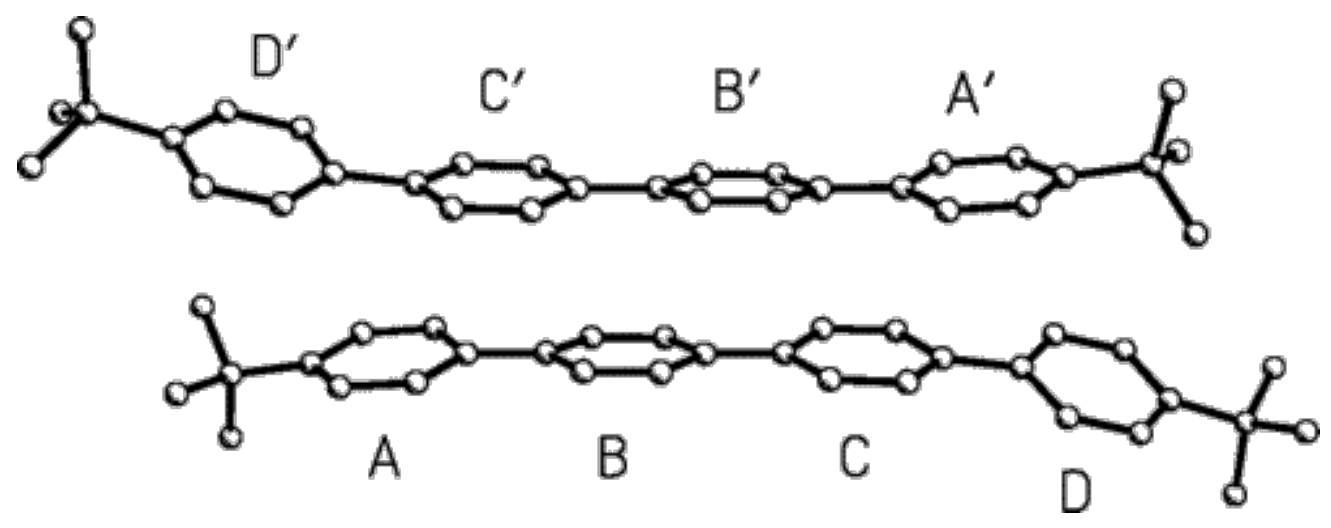

These salient features of the QP cation radical can only be rationalized, when one considers that the single charge is stabilized by a quinoidal valence bond resonance structure. Such a resonance form having a quinoidal structure leads to unequal bond distortions in the aryl rings as well as planarization 
of the aryl rings for effective $\pi$-conjugation with the magnitude of changes being the highest in the central rings. It is worthwhile to note that a previously reported ab initio SCF-LCAO-MO calculation of a lithium-doped quaterphenyl anion radical showed a similar quinoidal distortion as observed herein for the $\mathrm{QP}^{+\bullet} \cdot{ }^{14}$

In summary, the isolation and X-ray crystal structure determination of $\mathrm{QP}^{+\bullet} \mathrm{SbCl}_{6}^{-}$provides unequivocal evidence for the quinoidal stabilization of the cationic charge or polaron, which is responsible for the high conductivities in PPP oligomers in their doped state. The defect state induces regions of quinoidal conformation and thus serves as a physical model for the insulator-metal transition in PPP. ${ }^{3}$ Studies are underway for a more comprehensive investigation of the optoelectronic properties of PPP oligomers and will be reported in due course.

\section{Acknowledgment}

We thank the National Science Foundation (CAREER Award) for financial support.

\section{References}

(1) (a) Introduction to Molecular Electronics; Petty, M. C., Bryce, M. R., Bloor, D., Eds.; Oxford University Press: New York, 1995. (b) Maiya, B. G.; Ramasarma, T. Curr. Sci. 2001, 80, 1523-1530.

(2) Hide, F.; Garcia, M. A. D.; Schwartz, B. J.; Heeger, A. J. Acc. Chem. Res. 1997, 30, 430-436 and references therein.

(3) Shacklette, L. W.; Eckhardt, H.; Chance, R. R.; Miller, G. G.; Ivory, D. M.; Baughman, R. H. J. Chem. Phys.1980, 73, 4098-4102.

(4) Baur, J. W.; Kim, S.; Balanda, P. B.; Reynolds, J. R.; Rubner, M. F. Adv. Mater. 1998, 10, 1452-1455.

(5) Gale, D. M. J. Appl. Polym. Sci. 1978, 22, 1971-1976.

(6) (a) Bredas, J.-L.; Beljonne, D.; Coropceanu, V.; Cornil, J. Chem. Rev. 2004, 104, 4971-5003. (b) Martin, R. E.; Diederich, F. Angew. Chem., Int. Ed. 1999, 38, 1350-1377 and references therein.

(7) (a) Weiss, E. A.; Tauber, M. J.; Kelley, R. F.; Ahrens, M. J.; Ratner, M. A.; Wasielewski, M. R. J. Am. Chem. Soc. 2005, 127, 11842-11850. (b) Dance, Z. E. X.; Mi, Q.; McCamant, D. W.; Ahrens, M. J.; Ratner, M. A.; Wasielewski, M. R. J. Phys. Chem. B 2006, 110, 25163-25173. (c) Sun, D.; Lindeman, S. V.; Rathore, R.; Kochi, J. K. J. Chem. Soc., Perkin Trans. 2 2001, 1585-1594.

(8) Tolbert, L. M. Acc. Chem. Res. 1992, 25, 561-568 and references therein.

(9) The cation radicals of oligothiophenes, viologens, and Wurster's blue have been known to show shifts in the absorption bands at higher concentrations due to the formation of $\pi$-dimers; however, the $\mathrm{QP}^{+\bullet}$ did not show any change in its absorption spectra even when the concentration was increased 10-fold. (a) Mah, S.; Yamamoto, Y.; Hayashi, K. J. Phys. Chem. 1983, 87, 297-300. (b) Ueda, H. Bull. Chem. Soc. Jpn. 1968, 41, 2578-2586.

(11) The cation radical dimer pair in the solid state are most likely stabilized via a charge-resonance process, i.e., $\mathrm{QP}^{+\bullet}+\mathrm{QP}^{+\bullet} \leftrightarrow \mathrm{QP}^{++}+\mathrm{QP}$. For example, see: Kochi, J. K.; Rathore, R.; Le Magueres, P. J. Org. Chem.2000, 65, 6826-6836.

(12) Baudour, J.-L.; Délugeard, Y.; Rivet, P. Acta Crystallogr. 1978, B34, 625-628.

(13) Rubio, M.; Merchán, M.; Ortí, E. J. Phys. Chem. 1995, 99, 14980-14987. 
(14) Brédas, J. L.; Thémans, B.; André, J. M. Phys. Rev. B 1982, 26, 6000-6002. 